DOI: https://doi.org/10.30749/2594-8261.v3n2p109-124

\title{
TRABALHO ESCRAVO CONTEMPORÂNEO: VIOLAÇÃO AO PRINCÍPIO DA DIGNIDADE DA PESSOA HUMANA
}

\section{CONTEMPORARY SLAVE WORK: VIOLATION OF THE HUMAN PERSON DIGNITY PRINCIPLE}

Carla Sendon Ameijeiras Veloso*

Leonardo Rabelo de Matos Silva*

Resumo: O presente trabalho apresentou um breve resumo da história de como a escravidão se enraizou ao redor do mundo, apresentando os principais impactos às vítimas. O estudo passou pelo surgimento da escravidão no Brasil, a partir do descobrimento do País, pelo fortalecimento da prática com índios, depois os negros e, mais recentemente, com as populações mais vulneráveis, independente da raça, com o chamado trabalho escravo contemporâneo. Uma atividade que tem causado enormes prejuízos à dignidade humana, como também enfatizou este artigo e que, até hoje, nenhuma lei e nem políticas públicas conseguiram barrar por completo.

Palavras-chave: Escravidão Contemporânea. Dignidade da Pessoa Humana. Precarização de Direitos Sociais.

Abstract: The present work presented a brief summary of the history of how slavery was rooted around the world, presenting the main impacts to the victims. The study began with the emergence of slavery in Brazil, after the discovery of the country, by strengthening the practice with Indians, then the blacks and, more recently, the most vulnerable populations, regardless of race, with the so-called contemporary slave labor. An activity that has caused enormous damage to human dignity, as has also emphasized this article and that until today, no law nor public policies have managed to completely bar.

Keywords: Contemporary Slavery. Dignity of human person. Precariousness of Social Rights.

\footnotetext{
* Doutoranda em Direito pela Universidade Veiga de Almeida. Possui mestrado em Direito pela Universidade Católica de Petrópolis (2016). Atualmente é professora da Universidade Veiga de Almeida, professora da pós-graduação do Portal F3, da Universidade Cândido Mendes.

** Doutor em Direito pela UGF, Mestre em Direito e Economia, Bacharel em Direito pela UERJ e Advogado. Atualmente exerce o cargo de Pró-Reitor de Pós-graduação e Pesquisa da Universidade Veiga de Almeida, onde é Professor Titular IV e Coordenador do Programa de Pós-graduação Stricto Sensu em Direito - Mestrado e Doutorado (PPGD/UVA).
} 


\section{INTRODUÇÃO}

O presente artigo apresentará fatos e estudos que demostram a recorrência de atividades análogas à escravidão nos dias atuais: o chamado "trabalho escravo contemporâneo". O crime é caracterizado pela Lei $n^{\circ} 10.803 / 2003$ e pelo artigo 49 do Código Penal e afeta a vida de milhares de pessoas no Brasil, principalmente ao desrespeitar a dignidade da pessoa humana, tão evidenciada na Constituição Federal de 1988.

Inicialmente será feita uma abordagem sobre a evolução histórica da escravidão até a atualidade.

Abordaremos, também, o princípio da dignidade da pessoa humana, destacando como é tratada pela Carta da República e outros documentos jurídicos e segundo entendimento de juristas renomados, além de demonstrar como a dignidade tem sido negada às vítimas desse tipo de crime - por meio de casos e números.

Em relação aos casos, serão apresentados o da vítima José Pereira e da Fazenda Brasil Verde, que tiveram repercussão internacional, e a importância de cada um deles no combate ao crime no Brasil. Depois, o estudo vai apontar quantas e quem são os principais "escravos" da atualidade. Será abordado, ainda, o valor social do trabalho na dignidade do homem e o impacto da escravidão contemporânea nos direitos sociais.

Na sequência, o tema legislação será estendido com a descrição e análise das principais atuações do governo brasileiro, além de sinalizar uma recorrente ineficiência das ações de combate à prática no País.

A metodologia aplicada no presente trabalho, além dos estudos de caso, será a de pesquisa bibliográfica.

\section{EVOLUÇÃO HISTÓRICA DA ESCRAVIDÃO.}

Antes mesmo de analisar o prejuízo à dignidade da pessoa humana diante do trabalho escravo contemporâneo, é indispensável entender a origem desse tipo de prática, a chegada ao Brasil, a permanência na atualidade e como foi e até hoje é 
caracterizada, segundo as leis que regem o País. A princípio, destaca-se o fato de que a escravidão é muito mais antiga do que muitos imaginam. Segundo um dos historiadores e estudiosos sobre o tema, o brasileiro Jaime Pinsky, o escravismo é algo que ocorre mesmo antes de Cristo.

Na mesopotâmia e no Egito quando da execução das obras públicas como barragens ou templos grandes número de trabalhadores era recrutado. Tornava-se propriedade dos governantes que lhes impunham sua autoridade e determinavam as tarefas. Não eram, contudo, vendidos e sua atividade podiam cessar quando do fim da construção, retornando os trabalhadores as suas tarefas anteriores. As relações que estabeleciam com seus proprietários eram eventuais, diferentes daquelas que ocorriam na Gréciaprincipalmente Atena - e Roma onde a escravidão era a forma mais característica de extração de trabalho. Escravos eram comprados ou obtidos, após saques e batalhas e nunca perdiam- à exceção de casos isolados- sua condição. (PINSKY, 1993. p. 13.)

$\mathrm{Na}$ Bíblia Sagrada, entre os relatos mais conhecidos, estão os do antigo testamento. O Livro de Éxodo cap. 21, versículo 2 (BÍBLIA ONLINE, [2019a]), por exemplo, descreve a escravidão como uma "contratação" do povo do Egito. O trecho mencionado afirma que "se comprares um servo hebreu, seis anos servirá; mas ao sétimo sairá livre, de graça." Ou seja, a pessoa "contratada" era obrigada a trabalhar durante seis anos, para conseguir liberdade apenas no sétimo ano e sem receber nada. Vale destacar que, na época, as condições de trabalho eram muito precárias e as chances de saírem vivos dessas obrigações laborais também eram quase nulas. Também podem ser encontrados trechos bíblicos que relatam a escravidão na época de Jesus. No Livro de Efésios cap. 6, versículo 5 (BÍBLIA ONLINE, [2019b]), a escritura pede aos escravos que "obedeçam aos seus senhores" com respeito e temor.

Depois disso, é possível encontrar casos de escravidão em vários períodos, na Ásia, Europa, Américas e África. No Brasil, a escravidão foi quase que embrionária, surgiu paralelamente ao descobrimento. Apesar de ser um fato negado pela maioria da população, foram os índios os primeiros a serem escravizados no País. Segundo Márcia Gomes O. Suchanek, "o governo português desenvolveu, desde o início da colonização, um aparato jurídico administrativo para escravizar as populações nativas." (SUCHANEK, 2012), e o Brasil, na condição de país 
independente, deu continuidade a este processo escravista.

A explicação histórica para isso é que a busca por extrair riquezas do país, como o Pau-Brasil, e a falta da mão de obra naquela época levaram os portugueses a escravizar os habitantes daquela nova terra que estavam desbravando. Algo bem comum nos processos de descobertas, de acordo com o jurista brasileiro Agostinho Marques Perdigão Malheiro:

É um fato, infelizmente confirmado pela história, que desde a mais
remota antiguidade o vencedor ou conquistador, quando não matava
o vencido ou o prisioneiro, reduzia-o à escravidão. Pretendeu-se
mesmo que fosse esta última regra um progresso no Direito das
gentes, um ato de humanidade; no entanto que era realmente de
maior ferocidade por afetar já não exclusivamente o prisioneiro, e sim
indefinidamente toda a sua descendência. (MALHEIRO, 2008, não
paginado).

Em outro trecho do livro "Escravidão no Brasil: ensaio - histórico-jurídico Social", Malheiro destaca que portugueses chegaram, na época, a duvidar se os índios eram realmente da espécie humana, pois, na visão deles, os povos - que aqui estavam - eram considerados "escravos por natureza" (MALHEIRO, 2008). Foi o início ao desrespeito à dignidade da pessoa humana.

Ressalta Malheiro que o processo de escravização dos índios se perdurou por muito tempo, só começando a ser combatido em 1570, por meio da Carta Régia, a qual instituiu uma "abolição do Diretório dos Índios" (MALHEIRO, 2008), definiu a regra de "escravidão voluntária" dos mesmos ou obrigatória em caso de defesa da terra ou do Estado, caso se encontrasse em situação de ameaça ou vulnerabilidade. Mesmo assim, a legislação deixava muitas brechas, o que permitiu a permanência da prática. Em abril de 1757, por meio de um decreto de Marquês de Pombal, os índios deixaram "aparentemente" de ser escravos. As aspas na frase anterior têm motivos concretos, pois houveram evidências de escravidão indígenas até quase metade do século XX, como retratou o Relatório Figueiredo ${ }^{1}$, que apurou mortes e práticas de torturas contra indígenas em todo o País, cometidos por pessoas que deveriam, na verdade, proteger a população indígena.

\footnotetext{
${ }^{1}$ Relatório que apurou atrocidades praticadas por latifundiários e funcionários do extinto Serviço de Proteção ao Índio (SPI), encontrado em 2013, no Museu do Índio, no Rio de Janeiro. (BRASIL, 1967).
} 
Voltando ao século XVI, outros povos estavam sendo escravizados, quase que paralelamente aos índios. Isso porque, de acordo com a história do Brasil, entre os anos de 1539 e 1542, durante o ciclo da Cana-de-Açúcar, a escravidão dos negros foi automaticamente adotada com a chegada deles às terras brasileiras. Eles foram comercializados como mercadorias e sujeitos ao cumprimento de ordens. Segundo o advogado, estudioso do tema no País, Carlos Homero Vieira Nina, esses milhares de africanos que foram escravizados no Brasil, "[...] rasgaram as matas, lavraram o solo e fizeram a colheita dos produtos tropicais exportáveis; trabalharam nas minas, nos engenhos, nos portos e nas casas." (NINA, 2010, p. 63). Caso não as obedecessem dos donos, que os compravam, eram duramente punidos.

Segundo o cientista social, mestre em sociologia-política e doutorando em ciências sociais, Renato Cancian ([2015]), assim como ocorreu no caso dos índios, também houveram várias tentativas de libertar os africanos da escravidão. Um exemplo foi a Lei do Ventre Livre de $1881^{2}$, que determinou a libertação de filhos de escravas, e a Lei dos Sexagenários ${ }^{3}$, aprovada em 1885, que alforriou os negros com mais de 60 anos. Porém, essa suposta libertação, em tese, dos negros, só se deu em 1888, com a Lei Áurea, Lei imperial $n^{\circ} 3.353$, sancionada em 13 de maio daquele ano pela Princesa Isabel ${ }^{4}$, que declarou extinta qualquer tipo de escravidão no Brasil. No entanto, a Lei Áurea não foi capaz de acabar de vez com o trabalho escravo no Brasil. Segundo o escritor brasileiro, Euclides da Cunha (CUNHA apud PAIXÃO, 2017. p. 81), pouco tempo depois, sinais de escravidão apareceram em atividades econômicas que cresciam no país.

Na Amazônia no final do século XIX, começou um período conhecido como ciclo da borracha vegetal [...], A atividade de extração atraiu milhares de pessoas, brasileiras e quíchuas [...] atraídas pela esperança de uma vida melhor [...], nas novas e desconhecidas terras foram reduzidas a escravidão por dívida nos seringais. (CUNHA apud PAIXÃO, 2017. p. 81).

Atrás de muitos países desenvolvidos, o Brasil foi o último continente americano a abolir tal prática, nos moldes antigos. Afinal, a escravidão perdurou e

\footnotetext{
2 Lei $\mathrm{n}^{\circ} 2.040$, de 28 de setembro de 1871 (BRASIL, 1871).

${ }^{3}$ Lei $n^{\circ} 3.270$, de 28 de setembro de 1885. (BRASIL, 1885).

${ }^{4}$ Lei $n^{\circ} 3.353$, de 13 de maio de 1888. (BRASIL, 1888).
} 
perdura até hoje, com outras variantes, caras e formas, agora com o nome de "contemporânea". Esclarece Nina (2010, p. 63), fato que ocorre pelo mesmo motivo que provocou o início da escravidão no País: busca pelo poderio econômico. Destaca-se, com isso, que a prática atinge não somente as regiões rurais históricas áreas escravagistas -, como também, centros urbanos. Nessas localidades, existe exploração de trabalhadores tanto nas indústrias, como nas ruas, como o tráfico de mulheres à países estrangeiros para fins de prostituição em regime de escravidão, entre outros. (NINA, 2010, p. 63).

\section{O TRABALHO ESCRAVO CONTEMPORÂNEO NA LEI 10.803/2003}

Diante da permanência do trabalho escravo no Brasil, o Código Penal (CP) de 1940 trouxe, no artigo 149, a especificação do que é considerado trabalho escravo contemporâneo e a tipificação da conduta como criminosa. Mas o dispositivo reduziu a prática do crime a apenas quem submetia uma outra pessoa à "condição análoga à de escravo", sem dizer que condições eram essas. Como forma de resolver essas arestas legais, em 2003, após a intervenção da Comissão Interamericana de Direitos Humanos, no caso José Pereira (que será analisado adiante) foi sancionada, no Brasil, a Lei n 10.803, que alterou o artigo 149 do CP e passou a estabelecer penas ao crime nele tipificado e indicar as hipóteses em que se configura condição análoga à de escravo. Diz a lei, que alterou o artigo 149 do Código Penal de 1940.

Nota-se que o decreto retira o pensamento de que o trabalho escravo estava relacionado apenas à condição de restringir a liberdade. Conforme, o Procurador Federal Wesley Adileu Gomes e Silva, a norma evidência que o trabalho escravo também se estende a oferecer condições degradantes ao trabalhador. Referindo-se, por tanto, ao fato do empregador submeter pessoas a condições humilhantes de trabalho (SILVA, 2014). Em outras palavras, segundo a jurista brasielira Wiecko Volkmer Castilho, entende-se como o trabalho escravo toda e qualquer forma de labor que impacte negativamente a diguinidade da pessoa humana: "É, sem dúvida, um conceito mais amplo e mais apropriado à efetiva repressão das formas conteporâneas de escravidão." (CASTILHO apud PAIXÃO, 2017. p. 58). Por conta 
disso, segundo o Doutor em direito, José Claudio Monteiro de Brito Filho, todo trabalho com essas condições degradantes deve-se ser considerado escravo. Ele cita algumas situações:

Consderar-se-á trabalho escravo ou forçado toda modalidade de exploração de trabalhador em que esteja impedido, moral, psicológica e/ou fisícamente, de abandonar o serviço, no momento e pelas razões que entender apropriado, a despeito de haver, inicialmente, ajustado livrimente a prestação dos serviços.

A caracterização do chamado trabalho escravo conteporâneo ocorre não só diante de ameaças ou sanções, mas também mediante falsas promessas de boas condições de prestações de serviço e salário, ocasião em que o obreiro se apresenta espontaneamente para o labor.

A coação ocorre também, com retenção de documentos. É um importante elemento definidor deste tipo execrável de exploração. A coação pode ser moral, psicológica e fisíca. (FILHO apud PAIXÃO, 2017. p. 57).

Quanto às condições degradantes, Brito Filho discorre que ocorrem em todo trabalho em que o empregador nega ao trabalhador as condições básicas. Entre elas, o direito de trabalhar em jornada razoável e as garantias mínimas de saúde, segurança, trabalho, moradia, higiene, respeito e alimentação, tirando-lhes a dignidade (BRITO FILHO apud PAIXÃO, 2017).

Assim, diante dos argumentos, se faz necessário entender sobre o que é a dignidade da pessoa humana e como ela é afetada pelo trabalho escravo contemporâneo.

\section{A DIGNIDADE DA PESSOA HUMANA E O VALOR SOCIAL NO TRABALHO}

De acordo com o jurista Ingo Wolfgang Sarlet, o conceito de dignidade da pessoa humana existe há muito tempo. A afirmação pode ser observada, por exemplo, em documentos do Papa São Leão Magno, pontífice entre os anos de 440 e 461. Segundo Sarlet, o Papa, em um de seus pensamentos, sustentou que os seres humanos foram criados à imagem e semelhança de Deus, tornando o homem um ser especial, dotado de valor desde o nascimento (SARLET, 2012). Vários historiados e filósofos também contribuíram para o conceito da dignidade da pessoa 
humana. Entre eles, Immanuel Kant, que colocou a dignidade acima de qualquer outro direito, como destaca Ingo Wolfgang Sarlet:

[...] no reino dos fins tudo tem ou um preço ou uma dignidade. Quando uma pessoa tem um preço, pode pôr-se em vez dela qualquer outra como equivalente; mas quando uma coisa está acima de todo o preço, e por tanto não permite equivalente, então tem ela dignidade...Esta apreciação dá, pois, a conhecer como dignidade o valor de uma tal disposição de espírito e põe-na infinitamente acima de todo o preço. [...]. (KANT apud SARLET, 2012, não paginado).

Para Ingo Wolfgang Sarlet (2012, não paginado) o atual conceito de dignidade da pessoa humana pode ser definido como "[...] qualidade intrínseca e distintiva reconhecida em cada ser humano que o faz merecedor do mesmo respeito e consideração por parte do Estado e da comunidade". Para isso, segundo o jurista, é fundamental que Estado e Sociedade garantam "um complexo de direitos e deveres fundamentais que assegurem a pessoa tanto contra todo e qualquer ato de cunho degradante e desumano [...]. A partir das questões citadas acima, ele considera como dignidade da pessoa humana tudo aquilo que deve ser protegido, para que uma pessoa tenha condições mínimas de vivência e sobrevivência. (SARLET, 2012, não paginado).

No mundo jurídico, a dignidade da pessoa humana começou a tomar forma a partir de 1948, com a chegada da Declaração Universal dos Direitos Humanos, após o fim da Segunda Guerra Mundial. No documento, o valor da dignidade é destacado nos 30 artigos que Ihe completam. Logo no primeiro artigo, a carta ressalta que todas as pessoas são iguais "em dignidade e direitos." (ORGANIZAÇÃO DAS NAÇÕES UNIDAS, 2009, p. 4).

Conforme Ingo Wolfgang Sarlet, a Declaração de 1948 foi uma forma de os Estados Nacionais, reconfigurados no pós-guerra, assegurarem que os atos cruéis praticados durante a guerra - que mataram quase 50 milhões de pessoas - não fossem mais admitidos ou tolerados. Assim, a dignidade humana passou a ser um valor básico universal. (SARLET, 2012, não paginado).

No Brasil, a dignidade da pessoa humana ganhou respaldo e força após a promulgação da Constituição Federal de 1988. A Carta Magna coloca o Princípio da Dignidade da Pessoa Humana como o centro e fim do direito e a consolida no artigo 
$1^{\circ}$, inciso III, como um dos fundamentos da República Federativa do Brasil e do Estado Democrático do Direito. Assim, reforça Gabriela Delgado:

[...] a perspectiva da Constituição Federal de 1988 é de defesa e garantia dos direitos dos cidadãos, com base numa concepção ampliada dos direitos humanos, estabelecendo o compromisso do Estado, da sociedade e do governo de zelar por tais direitos. (DELGADO apud MIRAGLIA, 2015, posição 45).

Entre esses direitos mencionados na citação acima, lembra Lívia Mendes Moreira Miraglia, que estão os dos trabalhadores, que é elencado juntamente com a dignidade da pessoa humana pela Constituição ao status de direitos fundamentais que devem ser respeitados em todo o território nacional (MIRAGLIA, 2015, posição $64)$.

Como destacado nos parágrafos acima, o direito ao trabalho e a um meio ambiente de labor devidamente equilibrado e protegido foram expressamente destacados como direitos fundamentais sociais na Constituição Federal de 1988. No inciso IV, do artigo $1^{\circ}$, por exemplo, a Carta Maior consagra os valores sociais do trabalho e da livre iniciativa. Em seguida, no artigo $7^{\circ}$, estabelece os direitos dos trabalhadores urbanos e rurais com o intuito de proteger a relação de emprego e a dignidade de uma parte mais frágil: o trabalhador. (BRASIL, 1988).

Logo, fica claro que o trabalho escravo contemporâneo afeta a dignidade do empregado, como será exposto a seguir, por meio dos principais casos brasileiros.

\section{OS PRINCIPAIS CASOS E OS IMPACTOS À DIGNIDADE HUMANA}

\subsection{Caso José Pereira}

O primeiro caso de impacto internacional de trabalho escravo contemporâneo no Brasil foi o denominado "Caso José Pereira que ocorreu em 1989, na fazenda Espírito Santo, na cidade de Sapucaia no Pará, conforme evidência Cristiano Paixão:

Em setembro de 1989, a vítima, José Pereira, que contava, à época com 17 anos de idade, e outros 60 trabalhadores foram retidos contra sua vontade e forçados a trabalhar sem remuneração e em 
condições desumanas, degradantes.

Ao tentar escapar da fazenda, o adolescente José Pereira e outro trabalhador foram atacados com disparos de arma de fogo pelo "gato" [...].

Atingido em um dos olhos o adolescente caminhou até a sede da propriedade e pediu socorro. [...].

Depois o adolescente denunciou as condições de trabalho na fazenda à Polícia Federal. Sem resposta efetiva das autoridades, levou o caso às ONGs, que decidiram apresentar a denúncia à Organização dos Estados Americanos.

Em dezembro de 1994, as organizações não governamentais Américas Watch e Centro pela Justiça e o Direito Internacional (CEJIL) apresentaram uma à Comissão Interamericana de direitos Humanos contra a República Federativa do Brasil [...]. (PAIXÃO, 2017. p. 96).

Em entrevista em 2016 para o repórter Leonardo Sakamoto, site Repórter Brasil, a vítima José Pereira evidenciou as condições vividas, durante o tempo que passou na Fazenda Espírito Santo. Ao ser questionado sobre como era o tratamento dentro da fazenda, o jovem José Pereira citou, por exemplo, que trabalhavam de segunda a segunda, o dia todo, sempre sob ameaça. "A gente trabalhava com eles vigiando [...] armados com espingarda calibre 20. A gente dormia trancado, fechado, trabalhava a semana toda" (SAKAMOTO, 2004, não paginado), além de uma alimentação extremamente precária.

Diante das palavras da vítima, fica claro que nem mesmo o mínimo estabelecido pelas Leis brasileiras, para assegurar os direitos trabalhistas e a dignidade foram cumpridos, como segundo o artigo $6^{\circ}$ da Constituição Federal, que assegura a educação, a saúde, a alimentação, o trabalho, a moradia, a segurança, a previdência social, [...] (BRASIL, 1988, não paginado). Afere-se também, a negativa de vários direitos constitucionais, verificados, quando a vítima afirma, que trabalhava a semana toda, sem saber o quanto receberia por todo trabalho prestado.

Foi diante da certeza da retirada de direitos e da afetação à dignidade da pessoa humana, no caso José Pereira, que o Brasil, pressionado por organizações internacionais de Direitos Humanos começou a combater a prática, criando a lei 10.803/2003, já mencionada neste artigo. Além disso, também em 2003, o Estado brasileiro reconheceu a responsabilidade internacional do trabalho escravo sofrido pela vítima, José Pereira. Na ocasião, foi assinado o Relatório $N^{\circ} 95 / 03$, onde o Estado se comprometeu a cumprir uma série de compromissos relacionados ao 
julgamento e à punição dos responsáveis, modificações legislativas, medidas pecuniárias de reparação, de prevenção, de fiscalização e punição ao trabalho escravo, além de ações de conscientização contra o trabalho escravo (COMISSÃO INTERAMERICANA DE DIREITOS HUMANOS, 2003). Ainda em 2003, o Governo federal indenizou $\mathrm{R} \$ 52$ mil à José Pereira. Os empregadores ainda não foram julgados pelo crime, que é considerado imprescritível, por ser cometido mediante violações dos diretos humanos.

\subsection{Caso Fazenda Brasil Verde}

Outro caso emblemático que resultou na primeira condenação internacional do Brasil por trabalho escravo contemporâneo, é da Fazenda Brasil Verde, localizada no Município de Sapucaia, no Pará. Os proprietários do local empregaram vários homens entre 15 e 40 anos, para serem mão de obra escrava entre 1990 e 2000, segundo relata Cristiano Paixão:

Os trabalhadores, inicialmente, eram aliciados com falsas promesas e assinavam contratos e notas promissórias em branco. Ao chegarem à fazenda, percebiam que já possuiam divídas referentes aos gastos supostamete investidos pelo "gato" no seu transporte, o que configurava a situação de servidão por divída.

Pratica-se ainda, o sistema de "barracão" (truck system), cobrando se preços exorbitantes com alimentação dos trabalhadores, que acabavam devendo altas quantias em dinheiro [...], que tornavam impossível a liquidação da divída.

[...], os trabalhadores da Fazenda Brasil Verde também eram submetidos a trabalho forçado. (PAIXÃO, 2017, p. 98).

Ressalta Cristiano Paixão, que a ausência de uma investigação e punição fez com que o caso da Fazenda Brasil Verde chegasse até a Comissão Interamericana de Direitos Humanos em 2001. O processo foi longo. Apenas em 2016, o Brasil foi condenado pelo fato, sendo obrigada a ordenar medidas internas de reparação que incluem a retomada da investigação e o pagamento de indenizações aos trabalhadores afetados. (PAIXÃO, 2017, p. 99).

Na sentença da Corte Interamericana de Direitos Humanos (2016), consta que a condenação se deu por que o Brasil violou o direito de não submeter pessoas 
a escravidão e ao tráfico de pessoas, como estabelece o artigo 6.1 da Convenção Americana Sobre Direitos Humanos.

Conforme reportagem veiculada no site do Ministério Público Federal (BRASIL, 2018), para a Corte, não existiam dúvidas de que os trabalhadores eram mantidos na fazenda contra a vontade, por meio de ameaças, além de violência física e psicológica. Ainda de acordo com a notícia, era claro para a Corte que essas condições eram do conhecimento do estado brasileiro, que já tinha fiscalizado a fazenda e encontrado a mesma situação anteriormente. Segundo uma linha do tempo publicada pelo Ministério Público Federal, em pelos menos três grandes fiscalizações tinham sido feitas nos anos de 1993, 1996 e 1997 e "constatado a prática" (BRASIL, [2016]).

Após a primeira denúncia feita à Corte Interamericana de Direitos Humanos, em 2001, duas fiscalizações foram realizadas e até chegaram a resultar em dois processos criminais. Porém, em meio ao debate sobre a competência para julgar os casos de trabalho escravo e, por que não, a falta de "pulso firme" e prioridade nesse tipo de caso no País, um dos processos acabou extinto sem resolução. O outro foi enviado para a Justiça estadual na cidade de Xinguará, no Pará. "Depois disso, o inquérito desapareceu e não foi mais reinstaurado" (BRASIL, [2016]). Mesmo depois da grande condenação da Corte Interamericana, em 2016, nada sobre esses inquéritos foi encontrado.

No final de 2017, em mais uma tentativa de condenar os responsáveis e indenizar as vítimas do caso, a Procuradora-Geral da República, Raquel Dodge, assinou a Portaria $n^{\circ} 1.3260$ documento determina que seja criada uma "forçatarefa", com pelo menos quatro procuradores, para investigar "os crimes cometidos, com o objetivo de identificar, denunciar, processar e punir os responsáveis." (BRASIL, 2017, não paginado).

Observa-se, através da análise de casos que o Brasil foi um dos primeiros países a reconhecer, diante das Nações Unidas, a persistência de formas contemporâneas de escravidão. Foi o primeiro a criar uma política nacional efetiva de libertação de trabalhadores em 1995. O primeiro a lançar um plano integrado de combate ao crime (BRASIL, 2003) e a publicar, periodicamente, um cadastro de infratores a partir do mesmo ano. Criou o primeiro pacto empresarial em 2005 contra 
a escravidão e implementou ações pioneiras de repressão e prevenção que se tornaram referência no mundo. Contudo em 2017, tornou-se, contraditoriamente, o primeiro país a ser condenado pela Corte Interamericana de Direitos Humanos (2016) pela prática da escravidão contemporâneo.

\section{CONCLUSÃO}

No presente artigo evidenciou-se que o trabalho escravo contemporâneo existe até hoje, mesmo depois de tantas políticas e ações de combate à prática no País. Ao invés disso, aumentou o leque de vítimas, conforme apontaram pesquisas supracitadas neste artigo, passando a atingir pessoas de todas as raças, principalmente, as que tem menos recursos e escolaridade, que não tiveram e ainda não têm ajuda para alcançar uma vida melhor.

A vítima do trabalho escravo moderno perde sua dignidade, princípio assegurado pela Constituição Federal de 1988. Esta perda acontece por que o trabalhador explorado fica sujeito a condições degradantes, sem água potável, sem comida suficiente para matar a fome, dormitório adequado, alojado em ambientes sujos. Além disso, é forçado a trabalhar e ficar à mercê do empregador por dívidas. São situações que contrariam o princípio da dignidade da pessoa humana, indo contra tudoo que deve ser protegido na vida de uma ppessoa, para que viva de maneira satisfatória, segundo Ingo Wolfgang Sarlet.

Somado a isso há uma cultura do medo que é instaurada para evitar denúncias sobre a existência nos locais de trabalho escravo. Para combater a prática da escravidão contemporânea é preciso denunciar. Através das denúncias, o Ministério Público, o Ministério do Trabalho e a Polícia Federal iniciam um processo de investigações e de fiscalizações.

Apesar de todos os esforços resta constatada a existência em pelo século XXI de trabalho escravo contemporâneo em nosso território nacional.

Por fim, fica evidenciado que é preciso ações mais diretas, para abolir com a prática do trabalho escravo moderno no Brasil, como, por exemplo, cursos de capacitação profissional e com direcionamento para o mercado de trabalho. 


\section{REFERÊNCIAS}

BIBLIA ONLINE. Antigo Testamento. Livro de Êxodo. [S.I.], [2019a]. Disponível em: https://www.bibliaonline.com.br/acf/ex/21. Acesso em: 23 ago. 2018.

BIBLIA ONLINE. Novo Testamento. Livro de Efésios. [S.I.], [2019b]. Disponível em: https://www.bibliaonline.com.br/acf/ef/6/8. Acesso em: 13 nov. 2018.

BRASIL. [Constituição (1988)]. Constituição da República Federativa do Brasil de 1988. Brasília, DF: Presidência da República, 1988. Disponível em:

http://www.planalto.gov.br/ccivil_03/Constituicao/Constituicao.htm. Acesso em: 02 set. 2018.

BRASIL. Lei $\mathbf{n}^{\circ} \mathbf{2 . 0 4 0}$, de 28 de setembro de 1871. Declara de condição livre os filhos de mulher escrava que nascerem desde a data desta lei, libertos os escravos da Nação e outros, e providencia sobre a criação e tratamento daqueles filhos menores e sobre a libertação anual de escravos. Rio de Janeiro: Império do Brasil, 1871. Disponível em: http://www.planalto.gov.br/ccivil_03/leis/lim/LIM2040.htm. Acesso em 25 de ago. 2018.

BRASIL. Lei $\mathbf{n}^{\circ} \mathbf{3 . 2 7 0}$, de 28 de setembro de 1885 . Regula a extinção gradual do elemento servil. Rio de Janeiro: Império do Brasil, 1885. Disponível em:

http://www.planalto.gov.br/ccivil_03/leis/lim/LIM3270.htm. Acesso em: 25 de ago. 2018.

BRASIL. Lei $\mathbf{n}^{\circ}$ 3.353, de 13 de maio de 1888. Declara extinta a escravidão no Brasil. Rio de Janeiro: Império do Brasil, 1888. Disponível em:

http://www.planalto.gov.br/cCivil_03/LEIS/LIM/LIM3353.htm. Acesso em: 31 ago. 2018.

BRASIL. Portaria $n^{\circ} 1.326$, de 12 de dezembro de 2017. Diário Oficial da União: seção 2, Brasília, DF, ano 58, n. 239, p. 40, 14 de dezembro de 2017. Disponível em: http://www.in.gov.br/materia/-

lasset_publisher/Kujrw0TZC2Mb/content/id/1031974/do2-2017-12-14-portaria-n-1326-de-12-de-dezembro-de-2017-1031970-1031970. Acesso em: 06 de nov. 2018.

BRASIL. Comissão Especial do Conselho de Defesa dos Direitos da Pessoa Humana da Secretaria Especial dos Direitos Humanos. Plano Nacional para Erradicação do Trabalho Escravo. Brasília: OIT, 2003. Disponível em: https://reporterbrasil.org.br/documentos/plano_nacional.pdf. Acesso em: 04 set. 2018.

BRASIL. Ministério do Interior. [Relatório Figueiredo]. [Rio de Janeiro], 1967. Disponível em: https://pt.scribd.com/doc/142787746/Relatorio-Figueiredo. Acesso em: 31 de out. 2018. 
BRASIL, Ministério Público Federal. Caso Fazenda Brasil Verde. [Brasília, DF]: MPF, [2016]. Disponível em: http://www.mpf.mp.br/pgr/documentos/entenda-o-caso_fazenda-brasil-verde.pdf. Acesso em: 06 nov. 2018.

BRASIL, Ministério Público Federal. \#TrabalhoEscravoNão: após 18 anos, impunidade a crime na Fazenda Brasil Verde pode chegar ao fim. Procuradoria Geral da República, [S.I.], 31 jan. 2018. Disponível em:

http://www.mpf.mp.br/pgr/noticias-pgr/trabalhoescravonao-apos-18-anosimpunidade-a-crime-na-fazenda-brasil-verde-pode-chegar-ao-fim. Acesso em: 04 set. 2018.

CANCIAN, Renato. Abolição da escravatura: Brasil demorou a acabar com o trabalho escravo. Uol Educação. Pesquisa Escolar. [S.I.], [2015]. Disponível em: https://educacao.uol.com.br/disciplinas/historia-brasil/abolicao-da-escravatura-brasildemorou-a-acabar-com-o-trabalho-escravo.htm. Acesso em: 25 de ago. de 2018.

COMISSÃO INTERAMERICANA DE DIREITOS HUMANOS. Relatório n 95/03. Caso No 11.289 Solução amistosa José Pereira. 24 de outubro de 2003.

Washington: CIDH, 2003. Disponível em:

https://cidh.oas.org/annualrep/2003port/Brasil.11289.htm. Acesso em: 02 set. 2018.

CORTE INTERAMERICANA DE DIREITOS HUMANOS. Caso trabalhadores da Fazenda Brasil Verde vs. Brasil. San José, Costa Rica, 20 out. 2016. Disponível em:

http://www.itamaraty.gov.br/images/Banco_de_imagens/Sentenca_Fazenda_Brasil_ Verde.pdf. Acesso em: 04 set. 2018.

SILVA, Wesley Adileu Gomes e. Breves considerações sobre o crime de redução a condição análoga à de escravo. Revista Jus Navigandi, Teresina, ano 19, n. 4146, 7 nov. 2014. Disponível em: https://jus.com.br/artigos/29874. Acesso em: 1 set. 2018.

MALHEIRO, Agostinho Marques Perdigão. A Escravidão no Brasil: ensaio histórico-jurídico-social. Rio de Janeiro: EBooksBrasil, 2008. Disponível em: http://www.ebooksbrasil.org/eLibris/malheiros2.html. Acesso em: 31 ago. 2018.

MIRAGLIA, Lívia Mendes Moreira. Trabalho Escravo Contemporâneo: conceituação a luz do princípio da dignidade da pessoa humana. 2. ed. São Paulo: LTR, 2015.

NINA, Carlos Homero Vieira. Escravidão, ontem e hoje: aspectos jurídicos e econômicos. Brasília: ISBN, 2010.

ORGANIZAÇÃO DAS NAÇÕES UNIDAS. Declaração Universal dos Direitos Humanos. Rio de Janeiro: UNIC, 2009. Disponível em: https://nacoesunidas.org/wpcontent/uploads/2018/10/DUDH.pdf. Acesso em 01 de setembro de 2018. 
PAIXÃO, Cristiano et al. Combate ao Trabalho Escravo: Conquistas, estratégias e desafios. São Paulo: LTR, 2017.

PINSKY, Jaime. A Escravidão no Brasil. 12. ed. São Paulo: Contexto, 1993.

SAKAMOTO, Leonardo. Zé Pereira, um sobrevivente. Repórter Brasil. [S.I.], 02 jun. 2004. Disponível em:

https://reporterbrasil.org.br/2004/06/ze-pereira-um-sobrevivente/. Acesso em: 02 set. 2018.

SARLET, Ingo Wolfgang. Dignidade da Pessoa Humana e Direitos Fundamentais na Constituição Federal de 1988. Porto Alegre: Livraria do Advogado, 2012.

Kindle.

SUCHANEK, Márcia. Povos Indígenas no Brasil: de escravos à tutelados. Uma difícil reconquista da liberdade. Confluências, Niterói, v. 12, n. 1, p. 240-274, 2012.

Disponível em

http://www.confluencias.uff.br/index.php/confluencias/article/viewFile/92/111. Acesso em: 31 ago. 2018.

Recebido em 30/08/2019.

Aceito em 30/08/2019. 